\title{
PRODUÇÃO DE BIO-ÓLEO DE COCO VERDE, PALHA DE CANA, BORRA DE CAFÉ VIA PIRÓLISE.
}

\author{
M. D. BISPO ${ }^{1}$, C. DARIVA ${ }^{1}$, M. C. V. DE CAMPOS ${ }^{1}$, S. R. R. RAMOS ${ }^{2}$, e L. C. KRAUSE ${ }^{1}$ \\ ${ }^{1}$ Instituto de Tecnologia e Pesquisa - ITP, Núcleo de Estudo em Sistemas Coloidais - NUESC, \\ Universidade Tiradentes, Av. Murilo Dantas, 300 - CEP: 49030-230 - Aracaju - SE, Brasil \\ ${ }^{2}$ Embrapa Tabuleiros Costeiros, Av. Beira Mar, 3250 - CEP: 49025-040 - Aracaju - SE, Brasil \\ E-mail: mozartdaltro@hotmail.com \\ laiza_canielas@hotmail.com
}

RESUMO - Muitos pesquisadores vêm buscando ao longo dos séculos aprimorarem tecnologias que utilizem como matéria-prima materiais lignocelulósicos provenientes de áreas de reflorestamento e resíduos agroindustriais. Dentre as fontes de energia renováveis a biomassa é a mais promissora para gerar substâncias interessantes para a indústria química (fenóis, cetonas, aldeídos, álcoois, entre outros). Uma alternativa de quebra dos constituintes da lignocelulose é o processo de pirólise, o qual gera um produto líquido denominado bioóleo. Neste trabalho foi realizada a pirólise de três biomassas distintas (fibra de coco, borra de café e palha da cana) em um reator de leito fixo. O rendimento líquido em bio-óleo bruto no processo de pirólise foi de aproximadamente 37\%. A caracterização química dos bio-óleos obtidos, foi realizada por cromatografia gasosa acoplada à espectrometria de massa (GC/qMS). O bio-óleo de borra de café diferenciou-se dos demais por apresentar teores elevados de ácidos carboxílicos oriundos dos glicerídeos. No bio-óleo oriundo de casca de coco verde, verificou-se maior abundância de hidrocarbonetos alifáticos e aromáticos, e entre os compostos predominantes no bio-óleo de palha de cana de açúcar, destacaram-se os guaiacóis.

\section{INTRODUÇÃO}

No Brasil uma quantidade crescente de resíduos recebe destinação inadequada, ou seja, lixões a céu aberto ou aterros sanitários, comprometendo a saúde humana e o meio ambiente. Por esta razão, várias pesquisas têm sido realizadas no sentido de propor métodos alternativos que visem acompanhar a evolução do processo de urbanização, adequando soluções mais precisas às necessidades da sociedade (Park et al., 2012). 
O Brasil como maior produtor de cana de açúcar e café e, também, o quarto maior produtor de coco verde, é responsável pela geração de toneladas de resíduos por ano. De todo o café consumido, 99,8\% é resíduo denominado borra; cerca de $85 \%$ em massa do coco verde consumido em todo litoral Brasileiro é resíduo e $50 \%$ da palha de cana de açúcar (30\% em peso seco da planta) é deixada em campo, sendo o estante é incinerado (Martins e Jesus Jr, 2011; MORAES et al., 2007; Teixeira et al., 2011).

Uma das soluções sugeridas é a reciclagem em sistema fechado, porém estudos apontam processos termoquímicos para tratamento de resíduos, de modo a convertê-los em produtos com valor agregado, que certamente serão superiores ao dos resíduos. $\mathrm{O}$ processo abordado neste trabalho representa vantagens econômicas, e, simultaneamente ambientais, permitindo diminuir quantidades de resíduos (Bridgwater, 2012) .

Conforme estudos registrados na literatura, a pirólise vem sendo estudada, enfocando técnicas e parâmetros experimentais diferenciados para um melhor rendimento, porém, inexistem publicações em relação à comparação entre bio-óleos provenientes das biomassas estudadas neste trabalho.

\section{METODOLOGIA}

\subsection{Matérias-primas}

As biomassas utilizadas foram palha de cana-de-açúcar, borra de café e fibra de coco verde, adquiridas da fazenda localizada na cidade de Carmópolis em Sergipe, Empresa Maratá e da Empresa Brasileira de Agropecuária (EMBRAPA), da região dos Tabuleiros Costeiros, Aracaju, SE respectivamente. As amostras foram secas a $80^{\circ} \mathrm{C}$ em estufa até alcançar $10 \%$ de umidade, foram trituradas em um moinho de corte de marca SPLABOR Modelo MA-340, com granulometria entre 32 -60 mesh, armazenadas em recipiente de vidro.

\subsection{Análise Termogravimétrica da matéria-prima (TGA)}

A análise termogravimétrica das biomassas foi realizada em uma termo-balança (Shimadzu mod. TGA-60H, Japão), para qual $1,0 \mathrm{~g}$ da amostra foi aquecida entre 26 a $900^{\circ} \mathrm{C}$, com taxa de aquecimento de $10^{\circ} \mathrm{C} \cdot \mathrm{min}^{-1}$, em forno com atmosfera de nitrogênio (vazão média $=50 \mathrm{~mL} \cdot \mathrm{min}^{-1}$ ).

\subsection{Sistema de Pirólise}

Os experimentos de pirólise foram realizados em escala laboratorial (Modelo SDSLL, da BIOWARE, Campinas, Brasil). O sistema foi projetado em leito fixo visando altas taxas de transferências de calor, Na figura 1 está o esquema completo do pirolisador. 


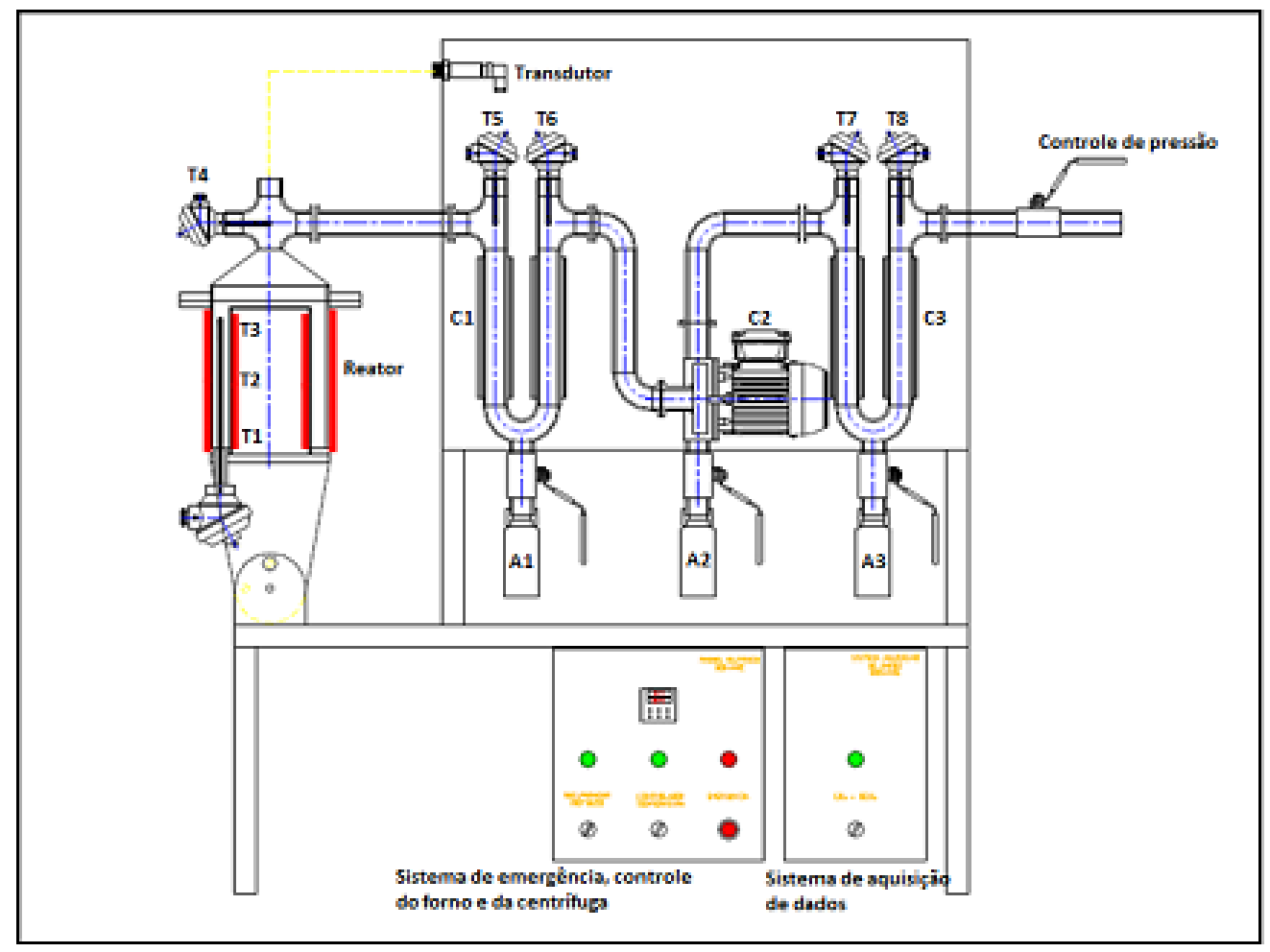

Figura 6: Esquema do Pirolisador usado neste trabalho, composto por um reator, um transdutor de pressão próximo ao reator, um controlador de pressão com válvula de esfera na saída do sistema, sistemas de controle de emergência (forno e centrífuga) e de aquisição de dados. Estão assinalados na figura os termopares do tipo $\mathrm{K}$ (T1 ao T8), os condensadores (C1 e C3 usados abaixas temperaturas e C3 com centrífuga) e os frascos coletores (A1 a A3).

As condições experimentais no sistema de pirólise: temperatura de $700^{\circ} \mathrm{C}$ utilizando resistências com uma potência de $6000 \mathrm{~W}$ dando uma taxa de $30^{\circ} \mathrm{C} / \mathrm{min}$, tempo de retenção de 15 min. Os produtos gerados após a pirólise foram resfriados até a uma temperatura de $1^{\circ} \mathrm{C}$ utilizando um sistema de condensadores. Após a pirólise foi realizada uma limpeza com propanona no interior dos condensadores.

Os rendimentos dos produtos condensados foram calculados utilizando a eq.1 com base na massa da amostra alimentada.

Eq.1 Cálculo de rendimento bruto em bio-óleo.

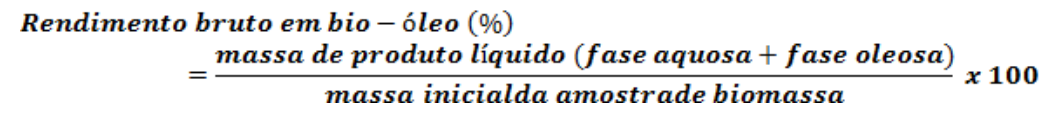




\subsection{Caracterização do bio-óleo por cromatografia gasosa acoplada a espectrometria de massas (GC/qMS)}

Os bio-óleos foram analisadas por GC/qMS (Shimadzu QP2010 plus, Shimadzu, Tóquio, Japão) equipado com um auto-injetor AOC20i .

A separação cromatográfica foi realizada utilizando uma coluna DB-5 $(30 \mathrm{~m} \times 0,25 \mathrm{~mm} . \times$ $0,25 \mathrm{~mm}$ ). A programção de temperatura foi de : $45^{\circ} \mathrm{C}(2 \mathrm{~min})$, aquecimento a $5^{\circ} \mathrm{C} / \mathrm{min}$ até $280^{\circ} \mathrm{C},(2 \mathrm{~min})$. A temperatura do injector e do detector foi de $280^{\circ} \mathrm{C}$, a injeção foi no modo splitless e o fluxo de gás (Hélio, ultrapuro, da Air products, Aracaju, SE, Brasil) foi de $1 \mathrm{~mL} \mathrm{~min}^{-1}$. Os dados foram tratados pelo software solução GCMS 2.6 (Shimadzu, Japão ).

\section{RESULTADOS E DISCUSSÕES}

\subsection{Análise Termogravimétrica (TGA)}

A Figura 2 apresenta as curvas TG/DTG (Análise Termogravimétrica / Derivada Termogravimétrica) das amostras de fibra de coco, borra de café e da palha de cana-de-açúcar respectivamente.
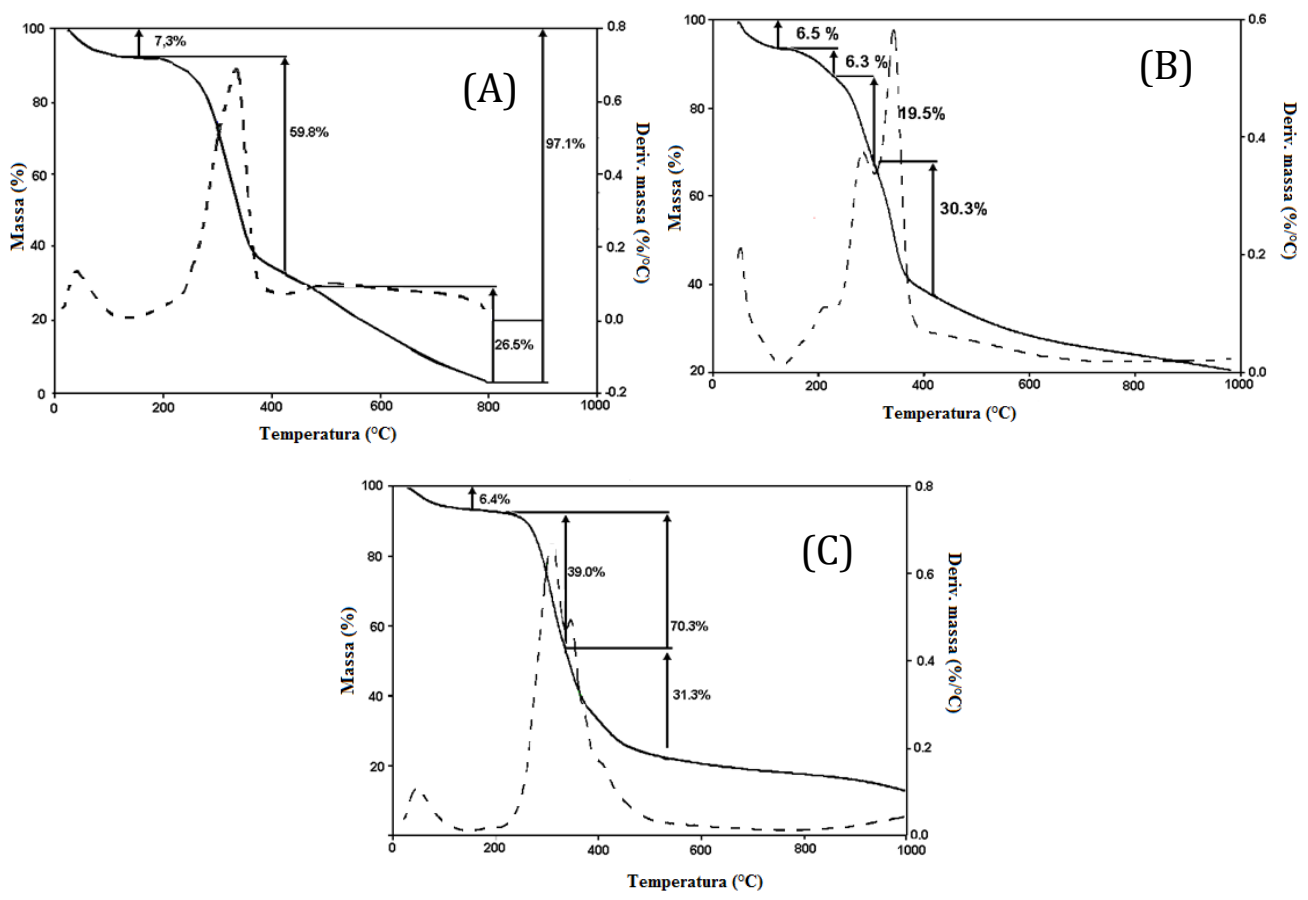

Figura 2 Termogramas das amostras onde (A), (B) e (C) corresponde a fibra de coco, borra de café e palha de cana-de-açúcar respectivamente. Condições cromatográficas descritas no item 2.2. 
A curva cheia indica o perfil de perda de massa (percentual em miligramas) e a curva tracejada na figura observa-se dois picos majoritários onde o primeiro pico aparece por volta de $100^{\circ} \mathrm{C}$, referente à evaporação de água e o segundo pico apresenta a maior perda de massa correspondendo à temperatura onde o conteúdo lignocelulósico das biomassas é esgotado (entre 200$500^{\circ} \mathrm{C}$ ), indicando um perfil pirolítico semelhantes para as biomassas estudadas entre as faixas 200$500^{\circ} \mathrm{C}$

A lignina, porém, é mais difícil de decompor completamente em temperaturas de $500^{\circ} \mathrm{C}$, apresentando perda de massa em um intervalo mais amplo de $160-900^{\circ} \mathrm{C}$ (Gronli et al., 2002; Sanchez-Silva et al., 2012). Isto é condizente com a temperatura máxima em que foi realizada a pirólise neste trabalho a $700^{\circ} \mathrm{C}$.

\subsection{Rendimento}

O rendimento em massa obtido para o bio-óleo bruto foi de 28,1\%, $30 \%$ e 29,9\% respectivamente para as biomassas fibra de coco, palha da cana e borra de café.

Observando que quantidades consideráveis de bio-óleo ficavam retidas no condensador podendo gerar um erro na medida do rendimento, foi feita a limpeza com $300 \mathrm{~mL}$ de acetona, aumentando assim o rendimento bruto em liquido dos bio-óleos da fibra de coco verde, palha de cana-de-açúcar e da borra de café em $36,8 \%, 36,1 \%$ e $35,2 \%$.

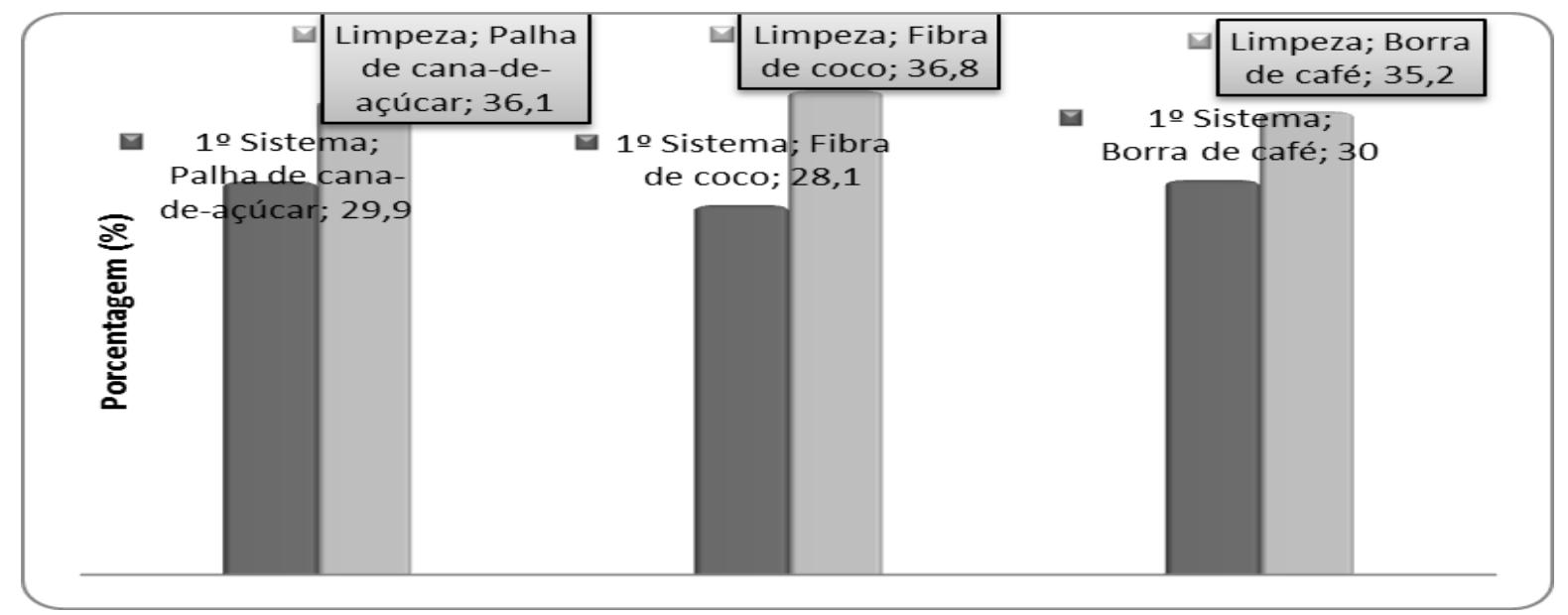

Figura 3: Variação do rendimento obtenção do bio-óleo considerando o sistema original ( $1^{\circ}$ sistema) e a Limpeza para as três biomassas pirolisadas a $700{ }^{\circ} \mathrm{C}$.

Os valores verificados para rendimento nesse estudo estão dentro da faixa de resultados encontrados na literatura (Tsai, et al., 2006; Sundaram, et al., 2009; Goyal, et al., 2008). 
Os resíduos sólidos (carvão e cinzas) resultantes da pirólise das três biomassas coletadas nos experimentos iniciais a $700^{\circ} \mathrm{C}$ apresentaram rendimentos em massa de 43,1\%, 44,5\% e 41,9\%, respectivamente.

\subsection{Análise Cromatográfica (GC/qMS)}

Os bio-óleos produzidos foram caracterizados por GC/qMS em triplicata e identificados tentativamente por comparação dos espectros de massas obtidos com os fornecidos pela biblioteca do equipamento (NIST 08s e NIST 27).

A figura 4 compara os cromatogramas, correspondendo ao perfil cromatográfico dos bioóleos de fibra coco verde, palha de cana de açúcar e da borra de café respectivamente na temperatura estudadas.

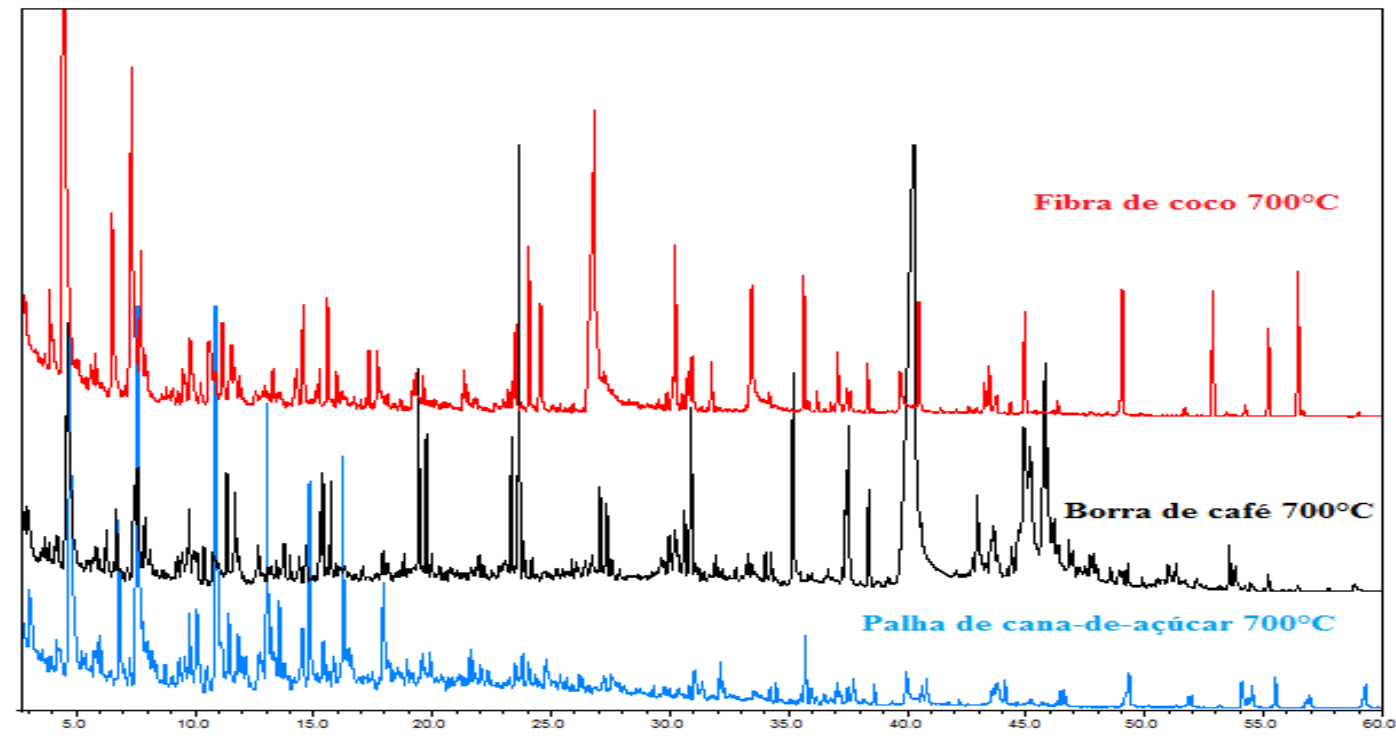

Figura 4 Comparação entre os cromatogramas gerados a partir dos três bio-óleos gerados. Condições cromatográficas descritas no item 2.4 .

Analisando-se as figuras 4 e a Tabela 1, percebe-se, que as classes dos compostos nos bioóleos são semelhantes e, observa-se a predominância na classe dos fenóis, característica de biomassas com maior percentual de lignina em acordo com Zhang, et al.., (2013), um elevado percentual de ácidos carboxílicos na borra de café, em função do teor de glicerídeos nessa biomassa, conforme Bok, et al., (2012).

Também foram detectados em maior percentual de área e picos no bio-óleo da fibra de coco, os hidrocarbonetos (aromáticos) e, no bio-óleo de palha de cana de açúcar, os fenóis. 
Tabela 1 - Resumo dos resultados obtidos pela caracterização por GC/qMS.

\begin{tabular}{lccc}
\hline Classe de compostos & Fibra de coco & $\begin{array}{l}\text { Palha de cana-de- } \\
\text { açúcar }\end{array}$ & Borra de café \\
\hline & 1 & Número de compostos & \\
\hline Álcool & nd & nd & nd \\
Ácidos & 1 & nd & 3 \\
Cetonas & 1 & nd & 1 \\
Éster & 1 & 1 & 1 \\
Éter & 8 & 12 & nd \\
Fenol & 10 & 4 & 4 \\
Hidrocarbonetos & & & 6 \\
Aromáticos & nd & 1 & 5 \\
Hidrocarbonetos Saturados & nd & 1 & 6 \\
Hidrocarbonetos Olefínicos & 2 & nd & 1 \\
Nitrogenados & & 19 & 27 \\
\hline $\begin{array}{l}\text { Total de compostos } \\
\text { identificados }\end{array}$ & 24 & & \\
\hline
\end{tabular}

\section{CONCLUSÕES}

Considerando o aproveitamento das biomassas procedentes dos resíduos da palha de cana-deaçúcar, borra de café e fibra de coco através da pirólise para produção de bio-óleo, os resultados experimentais indicam o potencial para utilização das biomassas estudadas como fonte geradora de produtos de interesse industrial (combustível, petroquímica, farmacêutica) além de reduzir o impacto ambiental causado pelo acúmulo das mesmas.

Os rendimentos em bio-óleo para as 3 biomassas foram semelhantes, porém no processo utilizado observou-se a necessidade de uma limpeza com solvente, no reator, evitando erros de medidas.

A análise via GC/qMS mostrou-se satisfatória, tanto na identificação quanto na semiquantificação das amostras indicando a diferença no perfil cromatográfico das mesmas. 


\section{REFERÊNCIAS}

BOK, J. P.; CHOI, H. S.; CHOI, Y. S.; PARK, H. C.; KIM, S. J., Fast pyrolysis of coffee grounds: Characteristics of product yields and bio oil crude quality Energy, 17-24, 2012.

BRIDGWATER, A. V., Review of fast pyrolysis of biomass and product upgrading. Biomass Bioenergy, 68-94, 2012.

GOYAL, H. B.; SEAL, D.; SAXENA, R. C., Bio-fuels from thermochemical conversion of renewable resources: A review, Renewable and Sustainable Energy Reviews, 504-517, 2008.

GRONLI, M.G.; VÁRHEGYI, G.; DI, BLASI C., Thermogravimetric analysis and devolatilization kinetics of wood. Industrial \& Engineering Chemistry Research, 4201-4208, 2002.

MARTINS, C. R.; JESUS JR, L. A., Evolução da produção de coco no Brasil e o comércio internacional: panorama 2010. Aracaju: Embrapa Tabuleiros Costeiros, 28 p. (Embrapa Tabuleiros Costeiros. Documentos, 164, 2011.

MORAES, M. A. F. D., O mercado de trabalho da agroindústria canavieira: desafios e oportunidades. Revista de Economia Aplicada, São Paulo, 605-619, 2007.

PARK, Y.; YOO, M. L.; LEE, H. W; PARK, S. H.; JUNG, S.; PARK, S.; KIM, S., Effects of operation conditions on pyrolysis characteristics of agricultural residues, Renewable Energy, 125130, 2012.

SANCHEZ-SILVA, L.; LÓPEZ-GONZÁLEZ, D.; VILLASEÑOR, J.; SÁNCHEZ, P.; VALVERDE, J. L., Thermogravimetric-mass spectrometric analysis of lignocellulosic and marine biomass pyrolysis. Bioresource Technology, 163-172, 2012.

SUNDARAM, E. G.; NATARAJAN, B. E., Pyrolysis of Coconut Shell: An Experimental Investigation, The Journal of Engineering Research, 33-39, 2009.

TEIXEIRA, A. L.; ROCHAR,. B.; RAMALHO, A. R., Melhoramento genético, registro e proteção de cultivares de Coffea canephora para o Estado de Rondônia, Empresa Brasileira de Pesquisa Agropecuária, Documentos 143, 2011.

TSAI, W., LIU, S., HSIEH, C., Preparation and fuel properties of biochars from the pyrolysis of exhausted coffee residue, Journal of Analytical and Applied Pyrolysis, 63-67, 2012.

ZHANG, Q.; CHANG, J.; WANG, T.; XU, Y., Review of biomass pyrolysis oil properties and upgrading research. Energy Convers Manage, 87-92, 2007. 